\title{
Spatiotemporal changes of cropping structure in China during 1980-2011
}

\author{
LIU Zhenhuan", "YANG Peng ${ }^{2}$, WU Wenbin', YOU Liangzhi ${ }^{3}$ \\ 1. School of Geography and Planning, Sun Yat-sen University, Guangzhou 510275, China; \\ 2. Key Laboratory of Agricultural Remote Sensing (AGRIRS), Ministry of Agriculture/Institute of Agricultural \\ Resources and Regional Planning, Chinese Academy of Agricultural Sciences, Beijing 100081, China; \\ 3. International Food Policy Research Institute, Washington DC 20006, USA
}

\begin{abstract}
Understanding the spatial and temporal variations of cropping systems is very important for agricultural policymaking and food security assessment, and can provide a basis for national policies regarding cropping systems adjustment and agricultural adaptation to climate change. With rapid development of society and the economy, China's cropping structure has profoundly changed since the reform and opening up in 1978, but there has been no systematic investigation of the pattern, process and characteristics of these changes. In view of this, a crop area database for China was acquired and compiled at the county level for the period 1980-2011, and linear regression and spatial analysis were employed to investigate the cropping structure type and cropping proportion changes at the national level. This research had three main findings: (1) China's cropping structure has undergone significant changes since 2002; the richness of cropping structure types has increased significantly and a diversified-type structure has gradually replaced the single types. The single-crop types-dominated by rice, wheat or maize-declined, affected by the combination of these three major food crops in mixed plantings and conversion of some of their planting area to other crops. (2) In the top 10 types, $82.7 \%$ of the county-level cropping structure was rice, wheat, maize and their combinations in 1980; however, this proportion decreased to $50.7 \%$ in 2011 , indicating an adjustment period of China's cropping structure. Spatial analysis showed that $63.8 \%$ of China's counties adjusted their cropping structure, with the general change toward reducing the main food types and increasing fruits and vegetables during 1980-2011. (3) At the national level, the grain-planting pattern dominated by rice shifted to coexistence of rice, wheat and maize during this period. There were significant decreasing trends for $47 \%$ of rice, $61 \%$ of wheat and $29.6 \%$ of maize cropping counties. The pattern of maize cropping had the most significant change, with the maize proportion decreasing in the zone from northeastern to southwestern China during this period. Cities and their surroundings were hotspots for cropping structural adjustment. Urbanization has significantly changed cropping structure, with most of these regions showing rapid increases in the proportion of fruit and vegetables.
\end{abstract}

Received: 2017-05-01 Accepted: 2017-10-15

Foundation: National Natural Science Foundation of China, No.41571172; Ministry of Finance of China through the Non-Profit National Research Institute, No.2017-CAAS-30

Author: Liu Zhenhuan (1982-), Associate Professor, specialized in landscape ecology and land use; global change and agricultural remote sensing. E-mail: zhenhuanliu@gmail.com

"Corresponding author: Yang Peng (1975-), Professor, specialized in global change and agricultural remote sensing. E-mail: yangpeng@caas.cn 
Our research suggests that the policy of cropping structural adjustment needs to consider geographical characteristics and spatial planning of cropping systems. In this way, the future direction of cropping structural adjustment will be appropriate and scientifically based, such as where there is a need to maintain or increase rice and wheat cropping, increase soybean and decrease maize, and increase the supply of fruit and vegetables.

Keywords: cropping structure; cropping type; cropping proportion; China

\section{Introduction}

Spatial and temporal information regarding cropping structure is an important basis for agricultural geography and sustainable agricultural development (Tang et al., 2010), especially in research on the terrestrial carbon emissions of agro-ecosystems, impact of global change on regional agricultural production, and dynamic mechanisms and simulation models of crop patterns (Waha et al., 2013; Liu et al., 2014; Tang et al., 2015). A sustainable cropping structure is beneficial for food security, agricultural resource utility and conservation (You, 2016). Cropping structure is based on the sown area of crops and consists of the ratio of each crop's sown area to the total sown area, and can be used to characterize historical variations, which can inform policymaking regarding the agriculture planting structure (Liang et al., 2008) and guide agriculture adaptation to climate change (Huang et al., 2012; Field et al., 2014; Guo, 2015; Zhou, 2015). Cropping structural adjustment is a part of macro-agricultural policies at the national level. Most previous cropping structure studies have been more concerned with policymaking, and few have focused on geographical characteristics of cropping structure (Liang et al., 2006). With the rapid development of society and economy, China's cropping structure has profoundly changed since the reform and opening up in 1978, but the pattern, process and characteristics of these changes have not been systematically shown. It is necessary to analyze the spatial and temporal changes of cropping structure to assess policies concerning food security and agricultural management (Hu et al., 2015).

Cropping structure is affected by natural conditions and socioeconomic changes and is characterized by spatial and temporal dynamics (Liang, 2006; Liu et al., 2013). Cropping structure contains information on one or more crops regarding continuous cropping, rotation, intercropping and other cropping patterns formed by the combination of cropping types (Hu et al., 2015). There are two types of data sources for cropping structure information: annual census data based on surveys from agriculture departments and remote sensing techniques for crop area monitoring (Wu et al., 2014). Remote sensing is increasingly being applied for quick surveys of cropping structure because of its timeliness and high resolution, and it can provide timely and accurate information at a fine scale (Wu et al., 2004; Xu et al., 2007; Cai and Cui, 2009; Huang et al., 2013; Liu et al., 2014). With advances in remote sensing technology, the monitoring of changes in cropping patterns in small regions has become more effective (Leff et al., 2004). However, there is limited capacity of remote sensing for large-scale monitoring, such as at the national or continental scale, because of cost and the short historical record. Compared to remote sensing data, administrative data often lags in time and its spatial resolution is fixed to the administrative boundary; however, such statistics have advantages at the national scale for quantifying the spatiotemporal variation of cropping pattern and are useful for analyzing historical changes in cropping structure (Li et al., 2008; Wang and Wang, 2015). Previous studies of cropping structure have focused on 
cropping structural adjustment policies, such as on the scientific way to adapt cropping structure to climate change ( $\mathrm{Li}$ and $\mathrm{Xu}, 2017$ ), cropping diversity (Aguilar et al., 2015; Hijmans et al., 2016; Deng et al., 2017) and cropping patterns (Huang et al., 2010; Xia et al., 2014; Zhang et al., 2017). The spatial and temporal changes of cropping structure is one component of cropping pattern studies, which describes cropping structure as crop type, composition and spatial distribution characteristics by use of cropping structure indicators in a specific region (Tang et al., 2010; Hu et al., 2015). The trend of crop types and cropping proportion, which are the most sensitive indicators of cropping structure used to evaluate adjustment policies, have not been yet considered by policy-makers (Liang, 2008). In order to quantify these cropping structure trends, we employed linear regression to analyze the trend of historical changes for different crop proportions at the county level in China. To reveal the pattern of cropping structure, a spatial overlay analysis was used to determine the counties with changed cropping combinations and their spatial characteristics.

China's cropping structure was previously the result of the long-term implementation of planned economy. Since the reforms, the cropping structure accompanying economic development has been adjusted and optimized (Ban, 2000). Rapid industrial and urban development has led to a decrease in the proportion of agriculture in the economy, as well as an adjusted cropping structure. China's agriculture has made great achievements, but further development faces the problem of deep cropping structural adjustments, especially concerning irrational proportions of agricultural production. Some cropping growing areas are dealing with environmental pollution and pest problems, which are large pressures on China's new round of cropping structural adjustments (Luo, 2015; You, 2016). Therefore, it is necessary to summarize the characteristics of cropping structure during the past 30 years to aid the new round of cropping structural adjustments. The main objectives of this research are to (1) analyze the changes and trends of cropping structure in China over the past three decades, (2) analyze the adjusted characteristics of cropping structure at the county level over the past three decades and clarify the geographical difference in cropping structure at the national level, and (3) understand the trend of cropping proportions and provide a basis of geographical clustering information for planning in the main agricultural regions. The above objectives differ from direct policy recommendations for the national cropping structural adjustment; we recommend more focus should be given to understanding the geographical characteristics of cropping structure, which may provide a scientific basis for cropping structural adjustment and food security policy.

\section{Data and methods}

\subsection{Data source}

(1) The county's cropping census database. Data at the county level for 1980-2011 were obtained from the Ministry of Agriculture and included each county's sown area data (http://www.zzys.moa.gov.cn/). Because many of the county boundaries changed several times during this period, the boundaries were merged into 2341 counties based on national county boundary data. Thirty-eight crop species were combined into 11 categories: rice, wheat, maize, soybean, potato, edible oil, fiber, sugar, cotton, vegetables and fruits. This comprised a dataset covering 32 years, 2341 counties and 11 crop types.

(2) Cropping type. In this research, the cropping type is defined as one of the crop species 
area as a percentage of the total crop area, which can be divided into two types: (i) if one crop's percentage is over $30 \%$, this crop can be accounted for by the cropping type. The combination is usually no more than three crops. For example, a county's crop sown area ranks on the top three, and only rice accounting for all cropping areas exceeds $30 \%$. This combination at the county level is the rice type. If two or three crops exceed $30 \%$ of the area, the combinations can be called the rice-maize type, rice-wheat-soybean type and so on. (ii) If the proportions of none of the crops exceed 30\%, then the top three crops are selected in combination. For example, if a county produces rice at $25 \%$, wheat at $24 \%$, soybean at $19 \%$ and maize at $17 \%$, the cropping type combination can be defined as rice-wheat-soybean. The combination of cropping type needs to consider the rank and proportion of crops. All the three crops can exist with variations in proportion in different counties, but if the crop is included in the combination, it is considered to be the same type. For example, rice-wheat-soybean is equivalent to wheat-soybean-rice or soybean-wheat-rice, and so on.

\subsection{Methods}

\subsubsection{Trends of cropping type}

To investigate the changes in cropping structure at the national level, this study defined a cropping type richness index $\left(R_{t}\right)$, which is the ratio of the cropping type occurring within a year to the types occurring in all years during the study stage. The expression is as follows:

$$
R_{t}=\frac{m_{t}}{m_{\max }}
$$

where $R_{t}$ has a range of $0-1$ and with a larger value meaning more abundance, $m_{t}$ is the amount for one year of the national cropping type and $m_{\max }$ is the total amount of all types of combinations within the study period.

\subsubsection{Trends of crop proportion}

To study the spatial and temporal characteristics of the cropping area and changes over the past 30 years, the slope coefficient $(S)$ was calculated by least squares regression to show the trends of the proportion of crops in 2341 counties. When $S<0$, this indicates that crops in these counties show a decreasing trend, and $S>0$ indicates an increasing trend; and if the test value ( $\mathrm{p}$-value) has a significance level of $0.05(\mathrm{p}<0.05)$, this is considered to be a significant trend. $S$ is calculated as follows:

$$
S=\frac{n \sum_{t=1}^{n} t X_{t j}-\left(\sum_{t=1}^{n} t\right)\left(\sum_{t=1}^{n} X_{t j}\right)}{n \sum_{t=1}^{n} t^{2}-\left(\sum_{t=1}^{n} t\right)^{2}}
$$

where $t$ is the study year time period, $n$ is the number of years and $X_{t j}$ is the ratio of crops for year $j$. We analyzed the changes in proportions of crops over the past 30 years.

\section{Results}

\subsection{Annual trends of cropping type}

Using the definition of cropping type, there was a total of 182 types during the past 30 years. 
Before 2000, the number of types was $21-54$, and $R_{t}$ was $0.12-0.30$; and after 2002, the corresponding values were $84-106$ and over 0.52 . The trends of $R_{t}$ showed an adjustment during 2000-2002, indicating that China's cropping types underwent significant changes and a sharp increase in richness of types. More diverse types have gradually replaced the simple types (Figure 1a). Thus, China's crop types underwent a shift to crop combinations, which have led to the main food crop pattern transforming to food and economic crop combinations.
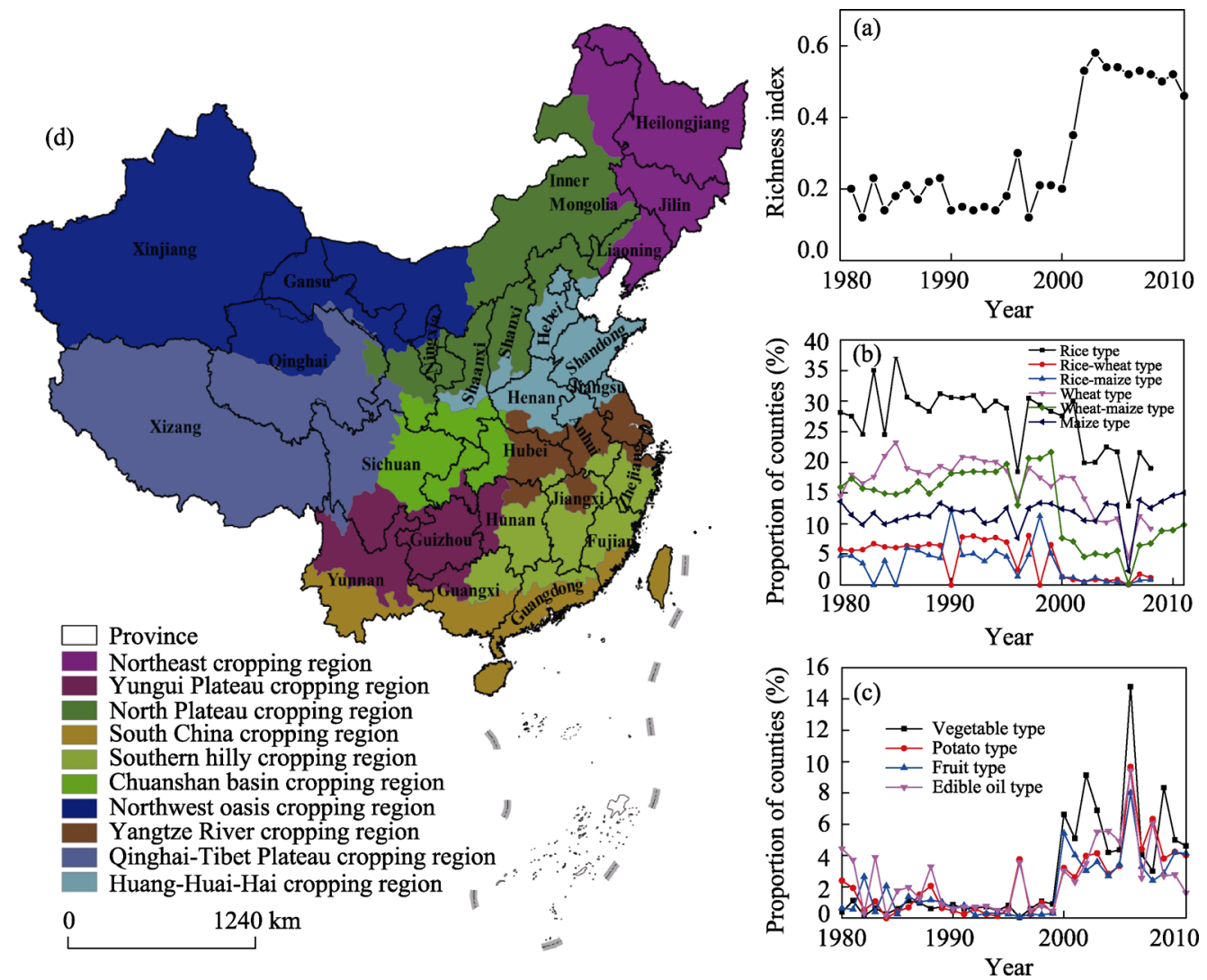

Figure 1 Study area and the richness and proportion of counties concerning cropping types in China during 1980-2011: (a) richness trend of cropping types, (b) and (c) trend of counties' proportions for specific cropping type, (d) study area and cropping zonal region

The eight major cropping types in China were rice, rice-wheat, rice-maize, wheat, wheat-maize, maize, vegetable and fruit types. Figure $1 \mathrm{~b}$ shows the trend of the three major food crops and their combinations. The three dominant single types of food crops decreased. The proportion of counties dominated by the rice type fell from the maximum of $37.5 \%$ in 1985 to $19.0 \%$ in 2008 , and the proportion of counties dominated by the wheat type decreased from $23.3 \%$ in 1985 to $8.8 \%$ in 2011 . The maize type was relatively stable around 10-14\%. The wheat-maize type remained within 15-20\% before 2002 and sharply decreased to $10 \%$ thereafter; the rice-wheat had a similar trend of $6 \%$ before 2002 and below $2 \%$ afterward. The rice-maize type was approximately $5 \%$ in 2002 , but less than $1 \%$ after 2002. Figure 1c shows the trend of the economic cropping types. The proportions of vegetable, potato, fruit and oil types were very low before 2000 , but were more than $2 \%$ after 2002. 


\subsection{Geographical variation of cropping type}

Over nearly 30 years, 16 crops made up the top ten major types (Table 1). In 1980, 82.7\% of China's crop types were rice, wheat, maize and their combinations and the top 10 of the country's cropping types at the county level accounted for $93.3 \%$ of all types, indicating that the three food crops were the major plantings. In 1990, the proportion of the top 10 rose slightly to $95.0 \%$ of all types; compared to 1980 , vegetable and fruit replaced soybean and cotton types in the top 10 . In 2000, the top 10 ranked of the cropping structure types decreased by nearly $10 \%$, reflecting that 209 counties changed their planting structure. In 2002 , the country's cropping structure underwent sharp changes, with a transition period during which the food crop proportion decreased. The main food type in the top 10 for all counties represented only $50.7 \%$. The number of counties of vegetable-type rose to be ranked fourth and accounted for $9.1 \%$. In 2011, there were 1699 counties in the top 10, accounting for only

Table 1 Proportions and amounts of cropping types in China during 1980-2011

\begin{tabular}{|c|c|c|c|c|c|c|c|c|c|}
\hline \multirow[b]{2}{*}{ Rank } & \multicolumn{3}{|c|}{1980} & \multicolumn{3}{|c|}{1990} & \multicolumn{3}{|c|}{2000} \\
\hline & $\begin{array}{l}\text { Cropping } \\
\text { type }\end{array}$ & $\begin{array}{l}\text { Coun- } \\
\text { ties }\end{array}$ & $\begin{array}{l}\text { Percent- } \\
\text { age }(\%)\end{array}$ & Cropping type & $\begin{array}{l}\text { Coun } \\
\text { ties }\end{array}$ & $\begin{array}{l}\text { Percent- } \\
\text { age }(\%)\end{array}$ & Cropping type & $\begin{array}{l}\text { Coun- } \\
\text { ties }\end{array}$ & $\begin{array}{c}\text { Per- } \\
\text { centage } \\
(\%)\end{array}$ \\
\hline 1 & Rice & 659 & 28.2 & Rice & 716 & 30.6 & Rice & 646 & 27.6 \\
\hline 2 & Wheat-maize & 373 & 15.9 & Wheat & 435 & 18.6 & Wheat & 413 & 17.6 \\
\hline 3 & Wheat & 340 & 14.5 & Wheat-maize & 426 & 18.2 & Maize & 291 & 12.4 \\
\hline 4 & Maize & 318 & 13.6 & Maize & 289 & 12.3 & Wheat-maize & 180 & 7.7 \\
\hline 5 & Rice-wheat & 136 & 5.8 & Rice-maize & 288 & 12.3 & Vegetable & 155 & 6.6 \\
\hline 6 & Rice-maize & 111 & 4.7 & Vegetable & 20 & 0.9 & Fruit & 127 & 5.4 \\
\hline 7 & Edible oil & 104 & 4.4 & Fruit & 15 & 0.6 & Potato & 75 & 3.2 \\
\hline 8 & Soybean & 62 & 2.6 & Edible oil & 14 & 0.6 & Edible oil & 71 & 3 \\
\hline 9 & Potato & 56 & 2.4 & Potato & 11 & 0.5 & Wheat-oil & 39 & 1.7 \\
\hline 10 & Cotton & 25 & 1.1 & $\begin{array}{c}\text { Rice-wheat-ma } \\
\text { ize }\end{array}$ & 9 & 0.4 & Rice-oil & 37 & 1.6 \\
\hline 11 & Others & 157 & 6.7 & Others & 118 & 5 & Others & 307 & 13.1 \\
\hline \multirow[b]{2}{*}{ Rank } & \multicolumn{3}{|c|}{2001} & \multicolumn{3}{|c|}{2002} & \multicolumn{3}{|c|}{2011} \\
\hline & Cropping type & $\begin{array}{c}\text { Coun- } \\
\text { ties }\end{array}$ & $\begin{array}{l}\text { Percent- } \\
\text { age }(\%)\end{array}$ & $\begin{array}{l}\text { Cropping } \\
\text { type }\end{array}$ & $\begin{array}{l}\text { Coun- } \\
\text { ties }\end{array}$ & $\begin{array}{l}\text { Percent- } \\
\text { age }(\%)\end{array}$ & Cropping type & $\begin{array}{l}\text { Coun- } \\
\text { ties }\end{array}$ & $\begin{array}{c}\text { Per- } \\
\text { centage } \\
(\%)\end{array}$ \\
\hline 1 & Rice & 703 & 30.0 & Rice & 466 & 19.9 & Rice & 468 & 20 \\
\hline 2 & Wheat & 409 & 17.5 & Wheat & 330 & 14.1 & Maize & 351 & 15 \\
\hline 3 & Maize & 282 & 12.0 & Maize & 247 & 10.6 & Wheat-maize & 230 & 9.8 \\
\hline 4 & Wheat-maize & 167 & 7.1 & Vegetable & 214 & 9.1 & Wheat & 207 & 8.8 \\
\hline 5 & Vegetable & 119 & 5.1 & Wheat-maize & 108 & 4.6 & Vegetable & 108 & 4.6 \\
\hline 6 & Fruit & 94 & 4.0 & Potato & 93 & 4 & Fruit & 97 & 4.1 \\
\hline 7 & Potato & 61 & 2.6 & Edible oil & 82 & 3.5 & Potato & 94 & 4 \\
\hline 8 & Edible oil & 54 & 2.3 & Fruit & 71 & 3 & Rice-vegetable & 59 & 2.5 \\
\hline 9 & Wheat-oil & 41 & 1.8 & Soybean & 51 & 2.2 & Cotton & 44 & 1.9 \\
\hline 10 & Rice-maize & 28 & 1.2 & $\begin{array}{l}\text { Rice-wheat- } \\
\text { maize }\end{array}$ & 36 & 1.5 & Rice-wheat & 41 & 1.8 \\
\hline 11 & Others & 383 & 16.4 & Others & 643 & 27.5 & Others & 642 & 27.4 \\
\hline
\end{tabular}


$72.6 \%$ of the total counties. In 1990, this number decreased in 524 counties $(22.4 \%)$. In this period, food crops and their combination with economic crop types appeared, such as the rice-vegetable type. After 2002, China's cropping types tended to be diverse, not only related to the adjustment of the national agricultural policy but also due to farmers' choices; for example, the types of food and fruit or vegetable crops surrounding urban areas were a consequence of urbanization.

The spatial distribution of cropping types within counties and over five time periods is shown in Figure 2. From the perspective of changes in crop type, $63.8 \%$ of the counties (1494) changed their type during 1980-2011. This trend entailed reducing the proportion of major food crops while increasing the proportion of economic crops and fruit and vegetable crops. These counties were mainly distributed in China's coastal and western regions; and the counties in which crop type was unchanged were in central China (Figure 2f). Only approximately one-third of the counties did not change their cropping type, with 385 of these of rice type, 105 of wheat type, 160 of maize type and 130 of wheat-maize type; however, the proportion of each dominant crop still had a decreasing trend.
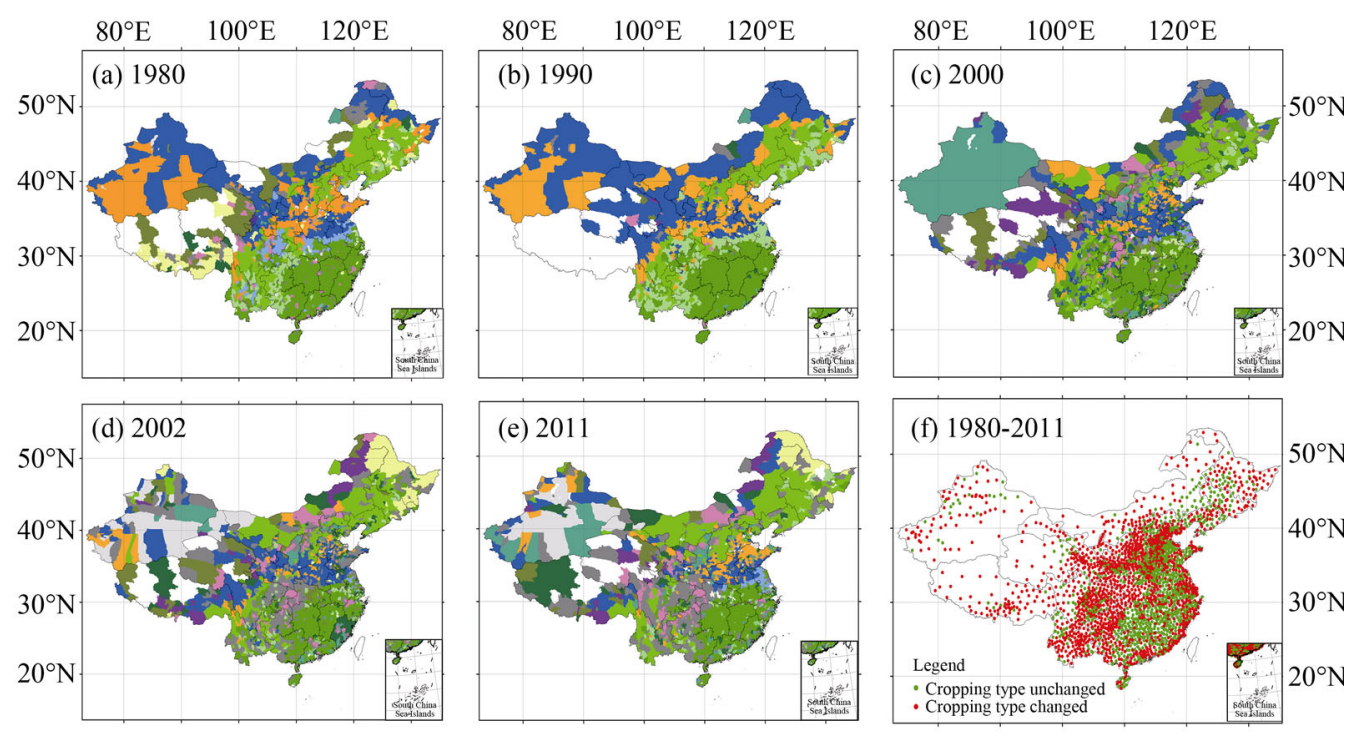

$$
\begin{aligned}
& 80^{\circ} \mathrm{E} \quad 100^{\circ} \mathrm{E} \quad 120^{\circ} \mathrm{E} \\
& 80^{\circ} \mathrm{E} \quad 100^{\circ} \mathrm{E} \quad 120^{\circ} \mathrm{E} \\
& \begin{array}{l}
\square \text { No data } \\
\text { Rice type } \\
\text { Wheat-maize type } \\
\text { Wheat type }
\end{array} \\
& \text { Maize type } \\
& \text { Soybean type Fruit type } \\
& \text { Rice-wheat type } \\
& \text { Potato type } \\
& \text { Rice-wheat-mize } \\
& \text { Rice-vegetable } \\
& \text { Rice-maize type } \\
& \text { Edible oil type } \\
& \text { Cotton type Wheat-edible oil type } \\
& \text { Vegetable type Rice-edible oil type }
\end{aligned}
$$

Figure 2 Spatial distribution of the dominant cropping types in China: (a) 1980, (b) 1990, (c) 2000, (d) 2002, (e) 2011, (f) county-level changes of cropping type

The number of counties in which the rice is the major crop type is declining, and the rice type is mainly distributed in 11 provinces of southern China. Most provinces have many counties, where their proportions have reduced, especially in the Yangtze River Delta, Pearl River Delta and Fujian urbanized areas. The maize type was mainly distributed from northeast to southwest. The wheat type was mainly distributed in northern Shandong, Xinjiang, Gansu, Ningxia, Inner Mongolia, central Henan, northern and southern Anhui, and Shandong in 1980; however, there was a relative decline in Henan, Anhui, and northern and part 
of southern Shandong in 2011. In 1980, the wheat-maize combination was mainly distributed in southern Hebei, central and northern Shandong, northern Henan, Shanxi, central Xinjiang and central, southern and northern Shaanxi; and this shrank in north-central Shandong, southern Hebei, northern Henan and southern Shanxi in 2011.

\subsection{Spatial distribution trends of crop proportions}

Figure 3 and Table 2 show the annual trends of crop proportions over the past 30 years. At the county level, the three staple food crop proportions tended to decrease; the $47 \%$ of rice, $61 \%$ of wheat and $29.6 \%$ of maize-planting counties significantly decreased $(p<0.05)$. At this stage, comparing the crop type change distribution (Figure 2), the pattern dominated by rice has changed to coexisting patterns of rice, wheat and maize and the proportion of other crops significantly increased.
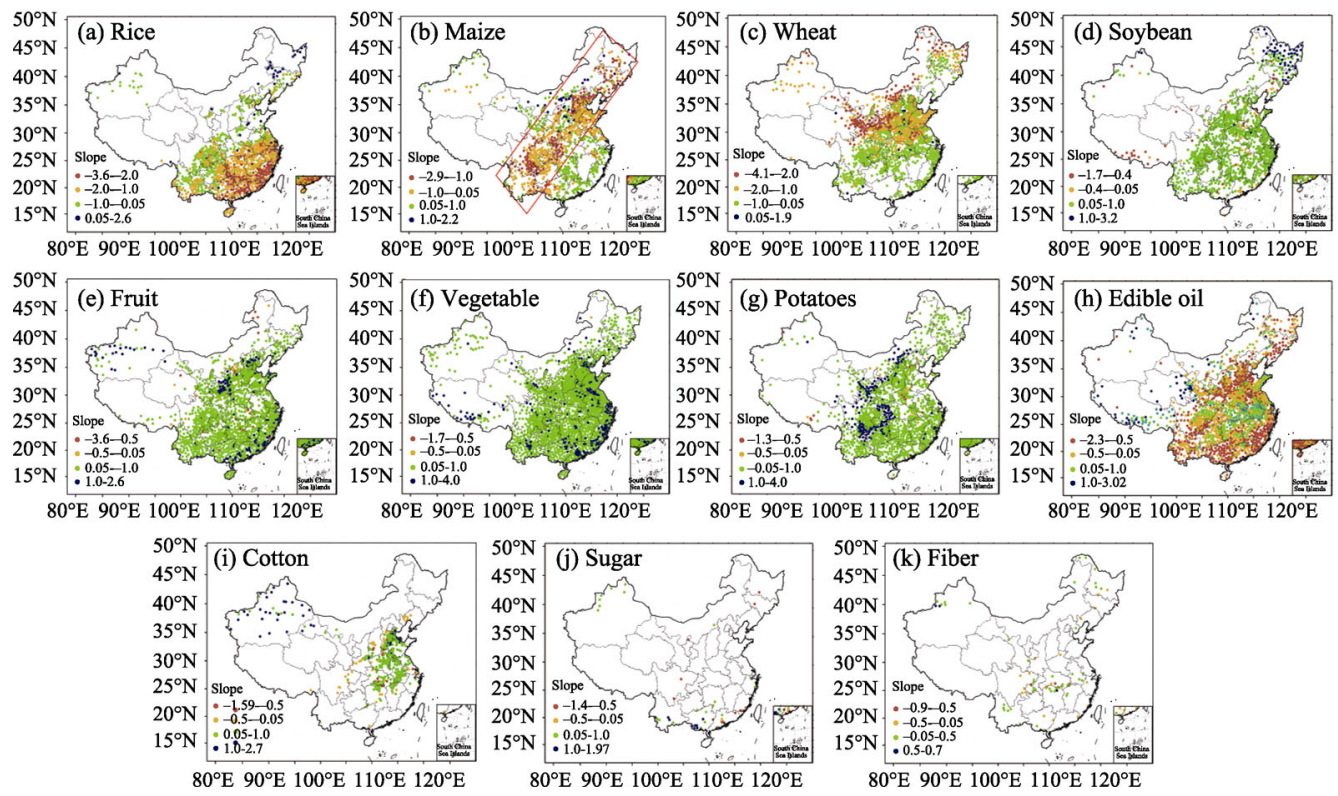

Figure 3 Spatial distribution of significant annual trends of cropping proportion in China during 1980-2011 ( $p$ $<0.05$ ): (a) rice, (b) maize, (c) wheat, (d) soybean, (e) fruit, (f) vegetable, (g) potato, (h) edible oil, (i) cotton, (j) sugar, (k) fiber

Regions with a significant reduction in rice proportion and rice type were mainly concentrated in Fujian, Guangdong, Zhejiang and other coastal provinces, whereas traditional rice-growing areas showed decreases in proportion but not in crop type, such as Jiangxi, Hunan, southern Anhui, Sichuan Basin and Chongqing. Regions with a significant reduction in the wheat-growing proportion and type were concentrated in the Loess Plateau region, including southern Gansu, Ningxia and the northern Shaanxi plateau to the Shanxi area; and the traditional wheat-growing region in the North China Plain also significantly decreased but did not change crop type. Regions with a significant reduction in maize proportion and type covered the China maize belt formation from northeast to southwest (Figure 3b); cropping type mainly changed in northern Yunnan, southern Sichuan, southern Shaanxi, western Hubei, Beijing, Tianjin and the northeastern plains area; and approximately 650 counties from northern Heilongjiang to southwestern Yunnan reduced their maize proportion. 
Table 2 Statistics regarding the annual trends of cropping proportions in China during 1980-2011

\begin{tabular}{|c|c|c|c|c|c|c|c|c|c|c|c|}
\hline \multirow[t]{2}{*}{ Crop } & \multirow{2}{*}{$\begin{array}{l}\text { County } \\
\text { number }\end{array}$} & \multicolumn{2}{|c|}{ No-trends } & \multicolumn{2}{|c|}{ Increasing trends } & \multicolumn{2}{|c|}{ Decreasing trends } & \multicolumn{2}{|c|}{$\begin{array}{l}\text { Significant in- } \\
\text { creasing trends } \\
\quad(p<0.05)\end{array}$} & \multicolumn{2}{|c|}{$\begin{array}{l}\text { Significant in- } \\
\text { creasing trends } \\
\quad(p<0.05)\end{array}$} \\
\hline & & $\begin{array}{l}\text { Coun- } \\
\text { ties }\end{array}$ & $\begin{array}{l}\text { Percen- } \\
\text { tage }\end{array}$ & $\begin{array}{l}\text { Coun- } \\
\text { ties }\end{array}$ & $\begin{array}{l}\text { Percen- } \\
\text { tage }\end{array}$ & $\begin{array}{c}\text { Coun- } \\
\text { ties }\end{array}$ & $\begin{array}{l}\text { Percen- } \\
\text { tage }\end{array}$ & $\begin{array}{l}\text { Coun- } \\
\text { ties }\end{array}$ & $\begin{array}{c}\text { Percen- } \\
\text { tage }\end{array}$ & $\begin{array}{c}\text { Coun- } \\
\text { ties }\end{array}$ & $\begin{array}{l}\text { Percen- } \\
\text { tage }\end{array}$ \\
\hline Rice & 2341 & 449 & 19.2 & 390 & 16.7 & 1502 & 64.2 & 46 & 2.0 & 1101 & 47.0 \\
\hline Wheat & 2341 & 178 & 7.6 & 217 & 9.3 & 1946 & 83.1 & 20 & 0.9 & 1429 & 61.0 \\
\hline Maize & 2341 & 88 & 3.8 & 1085 & 46.3 & 1168 & 49.9 & 417 & 17.8 & 693 & 29.6 \\
\hline Soybean & 2341 & 179 & 7.6 & 1778 & 76.0 & 384 & 16.4 & 1177 & 50.3 & 91 & 3.9 \\
\hline Fiber & 2341 & 1776 & 75.9 & 247 & 10.6 & 318 & 13.6 & 113 & 4.8 & 181 & 7.7 \\
\hline Cotton & 2341 & 1353 & 57.8 & 718 & 30.7 & 270 & 11.5 & 394 & 16.8 & 111 & 4.7 \\
\hline Vegetable & 2341 & 17 & 0.7 & 2271 & 97.0 & 53 & 2.3 & 2054 & 87.7 & 2 & 0.1 \\
\hline Potato & 2341 & 124 & 5.3 & 1983 & 84.7 & 234 & 10.0 & 1392 & 59.5 & 40 & 1.7 \\
\hline Fruit & 2341 & 104 & 4.4 & 2071 & 88.5 & 166 & 7.1 & 1656 & 70.7 & 40 & 1.7 \\
\hline Sugar & 2341 & 1040 & 44.4 & 572 & 24.4 & 729 & 31.1 & 57 & 2.4 & 18 & 0.8 \\
\hline Edible oil & 2341 & 34 & 1.5 & 2071 & 88.5 & 236 & 10.1 & 1627 & 69.5 & 17 & 0.7 \\
\hline
\end{tabular}

By contrast, economic crops, such as soybean, vegetable, potato, fruit and oil crops showed an increasing trend with $50.3 \%$ of soybean, $87.7 \%$ of vegetable, $59.5 \%$ of potato, $70.7 \%$ of fruit and $69.5 \%$ of oil cropping counties showing significantly increasing proportions $(p<0.05)$ (Figure 3). The increasing proportion of soybean was mainly in a few northeast China counties, such as central Heilongjiang and southern Jilin. Significant increases in the proportion of vegetables were concentrated in coastal regions, including Beijing, Tianjin, the Yangtze River Delta and the Pearl River Delta, and were closely related to urban demand - the others were located in the Shandong Peninsula, northern Jiangsu and northeast Guangxi. Significant increases in potato were mainly in central Inner Mongolia, southern Ningxia, Gansu and mountain regions in the five southwest provinces. Significant increases in fruit were mainly in Yantai, Beijing, the Loess Plateau, Xinjiang, Guangdong and Fujian. There were significant increases in the proportion of oil crops concentrated in southern Tibet, northern Xinjiang, eastern Qinghai, Hubei and Anhui.

In addition, cotton, sugar and fiber crops were regional crops; $42.2 \%$ of cotton, $55.6 \%$ of sugar and $24.2 \%$ of fiber showed significant spatial aggregation; $30.7 \%$ of cotton and $24.4 \%$ of sugar tended to significantly increase; and $13.6 \%$ of fiber tended to significantly decrease. Cotton significantly increased in Xinjiang, the North China Plain and the Yangtze River Plain (Figure 3i). Fiber is found along the Yangtze River. Sugar is scattered in Yunnan, Guangxi, Guangdong and Fujian (Figure 3k).

\subsection{Characteristics of cropping structure in urban regions}

To understand the impact of urbanization on regional cropping structure, the crop types of 717 counties surrounding 660 cities were used to analyze the trends of crop types and their proportions. Overall, the crop proportions in urban and surrounding areas were divided into two types of changes: The first was the crop sown area shrinking rapidly over the past 30 years. A large amount of arable land has been transformed into urban built-up land. Along with the land cultivated for food and forest land used for economic crops, $90 \%$ of counties 
lost cropland, with crop area decreasing rapidly and the fruit and vegetable area increasing rapidly. The second was cropping type shifting from early crops of rice or maize to crops of vegetables or fruit; $68.6 \%$ of the crop structure shifts occurred in these counties. Types of vegetables and fruit kept pace with urban expansion. In 1980, only three of 717 counties were vegetable-type, but there were 54 counties in 2011; and 13 counties were fruit-type in 1980 , but there were 29 in 2011 . Only 224 counties did not change their type, including 112 rice, 6 rice-wheat, 20 wheat, 48 wheat-maize and 31 maize types.

\section{Discussion}

\subsection{Cropping structure and food security}

The changes in cropping structure were closely related to the Chinese food security policy. The National Food Security and Long-term Planning Framework (2008-2020) established a scenario for 2020, with the aim to achieve a food self-sufficiency rate of $95 \%$ and top contain $100 \%$ cereals, which means the plan for the nation's cropping structure needs to carefully consider the food supply. As most relevant studies have found, cropping structure changes involve the following three aspects of food security: (1) The food price affects the food supply. Farmers tend to plant high-priced non-food crops or abandon land to go to cities to work. However, because of economic growth and the demand for high-quality of life from the Chinese population, an increasing number of people are choosing to eat more meat or protein, which requires more food to be used as feed. This will impact the staple food served in the future, food consumption habits, domestic and international food price changes, and regional land and water resource conditions. All of these will change the food demand. Relying on adjustments to cropping structure to achieve food production will be potentially limited. Therefore, food security is affected by the 2020 scenario (Huang et al., 2012). (2) To reduce greenhouse gas emissions and effectively protect the environment, an increasing amount of farmland will be returned to conservation land and the demand of biomass will increase the farmland needs (Suramaythangkoor and Li, 2012), which will directly affect the area of planted crops. This will aggravate the food supply crisis. It is suggested that an integrated policy of food security and cropping structural adjustment needs to be considered at the national level (Chen et al., 2014). This research shows that cropping structure changes are usually driven by the impacts of agriculture policies at the national level or by farmers' choices at the micro-level. (3) With urban development, an increasing amount of farmland is transformed to urban land and people in cities need more agricultural land to be transformed to tourism, which will change food crops to other crops. In addition, the tele-couple type cities' vegetable and fruit will drive farmer choices more than economic crops. All of these factors will reduce the food supply and change the cropping structure (Jiang et al., 2015).

\subsection{Factors influencing cropping structure}

Previous studies suggested that cropping structure changes were affected by combinations of agricultural policy, technological progress, social demand, economic growth and natural environmental conditions (Wang and Wang, 2005). Other studies proposed that, in addition, the impacts of urbanization and climate change were important. For example, Li et al.(2015) showed significant effects of urbanization level and climate change on rice cropping changes 
in China. However, in our study, crop structure changes did not follow a linear trend but showed a sharp change at a certain stage. Therefore, it is still difficult to quantitatively analyze the driving force.

From a qualitative perspective, there are several important factors: (1) Urbanization has changed the crop types in surrounding areas, replacing food crops with fruit or vegetables. (2) Food prices can drive the shift from low-value to high-value crops. (3) Technological advances will improve crop yields and sown areas and simultaneously reduce logistics costs and increase the crop demand exchange. (4) Agriculture investment has increased for nearly 30 years; in particular, agricultural inputs per unit enhance crop production and correspondingly reduce the demand for crop area. (5) Increased meat consumption has led staple crops to be used to feed livestock. (6) The effects of climate change need to be considered because studies have shown that nearly three decades of climate change have had a moderately positive effect on crop yields and sown areas (Ye et al., 2013; Liu et al., 2015). In the next 50 years, climate warming may move the boundaries for maize, winter wheat and double-cropping rice northward and these changes will provide a geographical space for crop structural adjustments (Liu et al., 2013; Ye et al., 2015). To this end, it is suggested that future research should consider the driving forces and so be able to explain the spatial and temporal changes in cropping structure.

\subsection{Policy implications for cropping structural adjustment}

Understanding the spatial and temporal changes of cropping structure is important for providing evidence-based policy recommendations for sustainable governance of cropping structure management at the national level. Our results show that cropping structure has undergone profound changes over the past 30 years, which not only changed the cropping types but also changed the cropping proportion trends in most counties. These two kinds of changes will help in understanding the national cropping type adjustment and specific crop adjustment policies. As shown in Figures 1d and 2, some remarkable suggestions can figure out in national level. It is necessary to increase soybean type and reduce the high-latitude maize type in the northeastern cropping region. In the North China Plain, wheat type should be maintained and maize reduced. Sugar and fruit types should be increased in the southern China cropping region. It is necessary to reduce wheat and expand potato and fruit in the northwest cropping region. In order to increase vegetable and fruit production to cope with the rapid demand from cities, the cropping area in urban surroundings should be increased. Our national policy suggestions concerning geographical characteristics of cropping structures are consistent with the views of Luo (2015), but with some spatial differences. However, for specific crops, we suggest that most of the counties with increased trends need to spatial aggregation to main cropping regions, such as sugar in the south, fiber in Yangtze River, cotton in the northwest and the North China Plain, soybean in the northeast and fruit in the northwest, the Loess Plateau and southern China (Figure 1d). The trends of cropping proportions and geographical clustering information will aid policy-makers in determining where and which crops are the best adjustment objectives. 


\section{Conclusion}

This study aimed to investigate the spatiotemporal changes in cropping structure in China during 1980-2011. Linear regression and spatial overlay were used to analyze the 11 major crops at the county and national scales. The results showed that geographical changes in cropping types occurred during 2002-2011 and cropping type richness doubled during 1980-2000. The staple food structure changed from being dominated by rice to coexistence of rice, maize and wheat. These deep changes showed a significant geographical shift of cropping types from grain types to grain, fruit and vegetable types. The spatial distribution of cropping proportion trends in counties showed that $47 \%$ of rice, $61 \%$ of wheat and $29.6 \%$ of maize cropping counties significantly decreased. These geographical characteristics of cropping structure suggest that the future direction of cropping structural adjustment needs to consider national adjustment in cropping types and specific crop proportion spatial aggregation policies. These findings will aid agricultural policy making departments in improving future scenarios of agricultural cropping structural adjustment. However, the future direction of cropping structural adjustment needs to consider not only geographical variation but also cropping variety and cropping regime.

\section{References}

Aguilar J, Gramig G G, Hendrickson J R et al., 2015. Crop species diversity changes in the United States: 1978-2012. PLOS One, 10: e0136580.

Ban Zhengyao, 2000. Crop planting structure adjustment: A food revolution of China in the 21st century. China Food Economy, (1): 13-15. (in Chinese)

Cai Xueliang, Cui Yuanlai, 2009. Crop planting structure extraction in irrigated areas from multi-sensor and multi-temporal remote sensing data. Transactions of the CSAE, 25(8): 124-130. (in Chinese)

Chen Yangfen, Zhong Yu, Liu Yu et al., 2014. Management situation and policy implications of China's grain security. Research of Agricultural Modernization, 35(6): 690-695. (in Chinese)

Deng X, Gibson J, Wang P, 2017. Relationship between landscape diversity and crop production: A case study in the Hebei Province of China based on multi-source data integration. Journal of Cleaner Production, 142: 985-992.

Field C B, Barros V R, Dokken D J et al., 2014. IPCC 2014: Summary for policymakers in Climate Change 2014: Impacts, Adaptation, and Vulnerability. Part A: Global and Sectoral Aspects. Contribution of Working Group II to the Fifth Assessment Report of the Intergovernmental Panel on Climate Change. Cambridge: Cambridge University Press, 17-18.

Guo Jianping, 2015. Advances in impacts of climate change on agricultural production in China. Journal of Applied Meteorological Science, 26(1): 1-11. (in Chinese)

Hijmans R J, Choe H, Perlman J, 2016. Spatiotemporal patterns of field crop diversity in the United States, 1870-2012. Agricultural \& Environmental Letters, 1: 160022.

Hu Qiong, Wu Wenbin, Song Qian et al., 2015. Recent progresses in research of crop patterns mapping by using remote sensing. Scientia Agricultura Sinica, 48(10): 1900-1914. (in Chinese)

Huang Jikun, Yang Jun, Qiu Huanguang, 2012. New Era of national food security strategies and policies. Issues in Agricultural Economy, 33(3): 4-8. (in Chinese)

Huang Qing, Tang Huajun, Wu Wenbin et al., 2013. Remote sensing based dynamic changes analysis of crop distribution pattern: Taking Northeast China as an example. Scientia Agricultura Sinica, 46(13): 2668-2676. (in Chinese)

Huang Qing, Tang Huajun, Zhou Qingbo et al., 2010. Remote-sensing based monitoring of planting structure and growth condition of major crops in Northeast China. Transactions of the Chinese Society of Agricultural Engineering, 26(9): 218-223. (In Chinese)

Jiang L, Seto K C, Bai J, 2015. Urban economic development, changes in food consumption patterns and land requirements for food production in China. China Agricultural Economic Review, 7(2): 240-261. 
Leff B, Ramankutty N, Foley J A, 2004. Geographic distribution of major crops across the world. Global Biogeochemical Cycles, 18(1): 1-27.

Li Kuo, Xu Yinlong, 2017. Study on adjustment of agricultural planting structures in China for adapting to climate change. Journal of Agricultural Science and Technology, 19(1): 8-17. (in Chinese)

Li Qifeng, Zhang Hailin, Chen Fu, 2008. Changes in spatial distribution and planting structure of major crops in Northeast China. Journal of China Agricultural University, 13(3): 74-79. (in Chinese)

Li Z, Liu Z, Anderson W et al., 2015. Chinese rice production area adaptations to climate changes, 1949-2010. Environmental Science \& Technology, 49(4): 2032-2037.

Liang Shumin, 2006. Space distribution and reason analysis of the changes in agriculture planting structure of China. Chinese Journal of Agricultural Resources and Regional Planning, 27(2): 29-34. (in Chinese)

Liang Shumin, Meng Zhe, Bai Shi, 2008. Research on Chinese crop planting structure changes based on village-level survey. Issues in Agricultural Economy, 29(Suppl. 1): 26-31. (in Chinese)

Liu J, Shen J, Li Y et al., 2014. Effects of biochar amendment on the net greenhouse gas emission and greenhouse gas intensity in a Chinese double rice cropping system. European Journal of Soil Biology, 65: 30-39.

Liu Kebao, Liu Shubin, Lu Zhongjun et al., 2014. Extraction on cropping structure based on high spatial resolution remote sensing data. Chinese Journal of Agricultural Resources and Regional Planning, 35(1): 21-26. (in Chinese)

Liu Z, Yang P, Tang H et al., 2015. Shifts in the extent and location of rice cropping areas match the climate change pattern in China during 1980-2010. Regional Environmental Change, 15(5): 919-929.

Liu Z, Yang X, Chen F et al., 2013. The effects of past climate change on the northern limits of maize planting in Northeast China. Climatic Change, 117(4): 891-902.

Liu Z H, Li Z G, Tang P Q et al., 2013. Change analysis of rice area and production in China during the past three decades. Journal of Geographical Sciences, 23(6): 1005-1018.

Luo Qiyou, 2015. Issue of A new round of strategic adjustment of crop planting structure. Source from: http://www.caas.cn/ysxw/zjgd/249662.shtml, 2015-10-13. (in Chinese)

Suramaythangkoor T, Li Z, 2012. Energy policy tools for agricultural residues utilization for heat and power generation. Renewable and Sustainable Energy Reviews, 16(6): 4343-4351.

Tang Huajun, Wu Wenbin, Yang Peng et al., 2010. Recent progresses in monitoring crop spatial patterns by using remote sensing technologies. Scientia Agricultura Sinica, 43(14): 2879-2888. (in Chinese)

Tang Huajun, Wu Wenbin, Yu Qiangyi et al., 2015. Key research priorities for agricultural land system studies. Scientia Agricultura Sinica, 48(5): 900-910. (in Chinese)

Waha K, Müller C, Bondeau A et al., 2013. Adaptation to climate change through the choice of cropping system and sowing date in sub-Saharan Africa. Global Environmental Change, 23(1): 130-143.

Wang Yang, Wang Xinjiang, 2005. Driving mechanism of cultivating structural evolutionary in Jilin province. System Sciences and Comprehensive Studies in Agriculture, 21(1): 34-36. (in Chinese)

Wu Bingfang, Fan Jinlong, Tian Yichen et al., 2004. A method for crop planting structure inventory and its application. Journal of Remote Sensing, 8(6): 618-627. (in Chinese)

Wu Wenbin, Yang Peng, Li Zhengguo et al., 2014. Overview of research progresses in crop spatial pattern changes. Chinese Journal of Agricultural Resources and Regional Planning, 35(1): 12-20. (in Chinese)

Xia T, Wu W, Zhou Q et al., 2014. Spatio-temporal changes in the rice planting area and their relationship to climate change in Northeast China: A model-based analysis. Journal of Integrative Agriculture, 13(7): 1575-1585.

$\mathrm{Xu}$ Mei, Ruan Benqing, Huang Shifeng et al., 2007. Monitoring of crop variety distribution by remote sensing and its application. Journal of Hydraulic Engineering, 38(7): 879-885. (in Chinese)

Ye L, Xiong W, Li Z et al., 2013. Climate change impact on China food security in 2050. Agronomy for Sustainable Development, 33(2): 363-374.

Ye Q, Yang X, Dai S et al., 2015. Effects of climate change on suitable rice cropping areas, cropping systems and crop water requirements in southern China. Agricultural Water Management, 159: 35-44.

You Fei, 2016. Discussion on several problems of current agricultural structure adjustment. Source from: http://www.caas.cn/xwzx/zjgd/276053.html, 2016-10-25. (in Chinese)

Zhang G, Xiao X, Biradar C M et al., 2017. Spatiotemporal patterns of paddy rice croplands in China and India from 2000 to 2015. Science of Total Environment, 579: 82-92.

Zhou Guangsheng, 2015. Research prospect on impact of climate change on agricultural production in China. Meteorological and Environmental Sciences, 38(1): 80-93. (in Chinese) 